\title{
Food For Thought: Exploring Students' Perspectives Of Assessment And Feedback
}

\author{
Rita Headington, Hetty Barron, Michael Smith and Duncan Callnon \\ University of Greenwich, School of Education
}

\section{Introduction}

This article reports on a case study exploring the students' perspective of assessment and feedback. The staff-student project discussed took place in 2010 and has since led to developments within the BA Primary Education (Qualified Teacher Status) at the University of Greenwich.

\section{The background}

The National Student Survey (NSS) has repeatedly shown student dissatisfaction with 'assessment and feedback' (HEFCE, 2011) across the higher education (HE) sector. Despite criticism of the NSS as a means of providing useful information (Cheng and Marsh, 2010), its place in key information sets documentation has raised the status of the NSS for HE providers.

Five NSS questions explore students' views of assessment criteria, the fairness of assessment arrangements and marking, the promptness and detail of feedback received and whether feedback has helped to clarify their understanding. In their address at the University of Greenwich, Nicol and Owen (2008) commented on the importance of improving the quality of assessment and feedback practice overall rather than focusing on the improvement of NSS statistics. With others (e.g. Rust et al., 2005), they advocated a social constructivist approach to HE assessment practices; moving from an emphasis on summative assessment for the purpose of certification alone (assessment of learning), to giving greater prominence to formative assessment, feedback and self-regulation (assessment for learning) (Sadler, 1989; Black and Wiliam, 1998; Hattie and Timperley, 2007). As Boud (2010) remarked, universities have focused on 'what students have achieved, rather than what they can achieve'.

\section{The problem}

Within this scenario, tutors in the Department of Primary Education developed practices to enhance the quality of provision in this area based on their working knowledge of assessment for learning in the schools' sector (Department for Education (DfE), 2011). They shared learning outcomes and discussed assessment criteria with students. Tutors also recognised that problems existed within the programme. Assignments were not always returned in time for students to use feedback for their next submission and some assignments were due for submission on the same day. However external examiners regularly praised the quality of written assignment feedback and the systems in place to provide consistency of practice between markers. Tutors' and students' evaluations seemed to indicate a mis-match between the views each group 
held of assessment and feedback practices. NSS scores in this area remained consistently disappointing for the programme.

\section{What we did}

To investigate the perceived mis-match, a collaborative tutor-student 'Dragons' Den' project was run by and for undergraduate students in 2010 to explore students' perspectives of the assessment and feedback they experienced within the programme. The project was developed and run by a team comprising three members of staff (project leader, staff/student liaison and researcher) and five student ambassadors.

A World Café (2011) approach, which aids the facilitation of large-group discussion, was chosen as a means of learning more about students' perspectives through 'conversations that matter' (Brown and Isaacs, 2005), as it involves and values participants and gives them an opportunity to influence future developments (Sheldon and Burke, 2010). This approach has been used in the university to explore key themes in an informal atmosphere but is not without its problems. Appropriately timed events, a relaxed atmosphere and the availability of participants is fundamental, but outcomes rest on the clarity of the questions asked, the skills of those leading the discussions and the experiences and the points raised by those who choose to attend. The World Café offers insight rather than a definitive response.

\section{The World Café events}

Four statements/questions were designed by the project team to provoke discussion. They were derived from the NSS assessment and feedback statements and based on local need:

"I prefer to be assessed by..."

"I like to get feedback from..."

"How do you feel about, or use, success criteria'?"

"Feedback is most useful to me when..."

Three World Café events were organised to coincide with students' availability before or after whole cohort lectures. The student ambassadors took responsibility for these events and prepared by grouping tables, placing paper tablecloths with pens and one of the above statements/questions on each table and organising refreshments for participants. When students arrived the ambassadors explained the discussion activity, the use of the tablecloths as note pads and the need for participants to circulate between tables and discussion themes. Ambassadors took the role of group moderators, staying at tables to provoke or summarise discussion. Staff organised rooms and refreshments and advertised the events but did not attend them as their presence may have inhibited discussion.

Sixty students attended the World Café events, from a population of some 340 . The annotated tablecloths were passed onto the project's researcher who transcribed the comments and analysed them by identify emerging themes. Findings were discussed with the ambassadors who provided additional insight into the context of discussions and the meaning of students' written comments. From this a draft report was written, agreed with ambassadors and presented to the project team.

${ }^{1}$ Success criteria: statements used to help identify when learning has been successful. These are a feature of Assessment for Learning in primary education, see DfE (2011). 


\section{What we found}

The main findings were in the four areas of timeliness of feedback, clarity in feedback, personalised feedback and assessment strategies.

Firstly, students wanted feedback to occur during the learning process when ideas were fresh in their minds, enabling the connections between feedback and learning through formative dialogue (Hattie and Timperley, 2007; Nicol, 2010). Students commented that this level of feedback occurred regularly during school-based placements, through contextualised discussions with their school-based mentors and university-based link tutors, but that this practice did not translate easily into the assignment submission process. Marking and quality assurance requirements appeared to create distance between submission and feedback. The timing of assignments was also considered problematic. Bringing into focus Black and Wiliam's (1989) findings in this area, students said they wanted sufficient time between feedback from one assignment and submission of the next to enable them to reflect on the feedback received and consider how to use it in later assignments.

Secondly, to support their development students said they wanted greater clarity in their feedback, suggesting it should be closely linked to success criteria, with clear targets for improvement and the specification of 'next steps'. This has resonance with Sadler (1989) who stated that, "feedback needs to provide information specifically relating to the task or process of learning that fills a gap between what is understood and what is aimed to be understood". Students perceived such detailed and targeted feedback to be more evident within school-based placements than in the academic element of their studies.

Thirdly, it was apparent that students valued the one-to-one nature of the feedback they received on schoolbased placement. They recognised the difficulties of replicating such personalised feedback within the university context but felt that tutors should be available to discuss their feedback when work is handed back.

Lastly, students wanted assessment strategies to move beyond written coursework to encapsulate activities they considered to be more authentic to the teaching profession, such as presentations, oral assessments and practical teaching activities. One particular comment stated that the strategies should assess students 'ability to teach rather than just abstract theory'. This remark encapsulated the main finding that emerged from analysis of the World Café discussions; that students were separating their school-based placement and academic studies rather than seeing direct inter-relationship between them, with the latter providing a theoretical underpinning for their work as teaching professionals.

\section{Food for thought}

The project team's findings and emerging themes were disseminated to tutors at the July 2010 departmental development day. To supplement this, the student ambassadors shared the annotated tablecloths with tutors and expanded on issues identified by the World Café participants. The students' perspectives gave tutors particular food for thought about the interplay between the academic and school-based elements of the programme.

Although tutors had recognised some assignments were poorly timed they had not fully acknowledged the detrimental impact this had on the students' learning experiences, especially where formal opportunities to gain formative feedback did not exist in a course. This did not apply in school-based placements where formative assessment features regularly, building to a summative end-point assessment.

Similarly, although the quality of academic written feedback met with the approval of examiners it did not always provide students with the opportunity to understand and apply it to future assignments across a 
range of courses. Conversely, students were able to make immediate use of the feedback they received in placements and, due to its nature as mainly oral, contextualised and developmental, they could see immediate relevance and application.

\section{How the findings were used}

Tutors discussed the findings and determined that developments were needed in relation to assignment feedback and students' professional development and two working groups were formed to develop practice in these areas. The first group redesigned the assignment feedback sheets and explored how assessment and feedback could be emphasised as a process, rather than a product, to aid understanding. The group determined to involve students in this process by asking them to identify areas where they would like specific feedback and making greater use of assessment criteria descriptors. It recommended that descriptor grids (showing expectations of each assessment criterion at each degree classification level) be developed and used in every course. These would not only form the basis for consistent marking between tutors but would be shared with students to increase levels of transparency and mirror similar practices within school-based placement assessment. Through a range of activities, students would be given a greater understanding of, and involvement in, academic standards applied throughout the three levels of the degree. Students would be able to examine the grids to determine how to improve the quality of their work; encouraging greater selfregulation in their learning. The group also recommended overt reference to different types of feedback be used within courses and an analysis of assessment practices at programme level undertaken to avoid sameday submissions and ensure students had sufficient time to use the feedback from one assignment to inform the next.

The second group explored the role of a professional development course in helping students to use their feedback and make more effective use of tutor availability. The group recommended sessions, of two personal tutors and their 16-18 tutees, be timetabled in each year of the degree. The sessions would have a different focus each year whilst requiring students to critique their feedback from all academic assignments and school-based placements in respect of their academic progress and the 'Qualifying to Teach' standards (Training and Development Agency for Schools, 2011). It was felt this would encourage students to view their professional development as active and serve to emphasise the relationship between the theoretical and practical aspects of the programme. The course would require students to consider their progress as reflective practitioners who are able to appraise their work, determine actions and track their achievements, ultimately preparing them for the professional experience of teaching.

The work-group's recommendations were presented and agreed at department meetings to inform the 2010-11 academic year. To 'close the loop', and ensure that students recognised the value of their World Café event contributions, the student ambassadors disseminated the project's findings from the events and the department's consequent actions to all student cohorts during Autumn 2010.

\section{Closing thoughts}

Although the project has given insight into the students' perspective of assessment and feedback and led to developments in practice, there is recognition that more work is necessary. The staff and students' perspectives and the programme requirements will change. The developments identified are not faultless and will, in due course, need to be reviewed and revised. But the project has provided us with a cycle of activity that has enabled students' perspectives to be identified and used to develop their experiences of assessment and feedback. 


\section{Acknowledgements}

We wish to acknowledge the University of Greenwich's Innovation Funding which provided funding for this project.

\section{References}

Black, P., and Wiliam, D. (1998) Assessment and Classroom Learning. Assessment in Education: Principles, Policy \& Practice, 5 (1), pp.7-74.

Boud, D. 2010. The New Assessment Agenda: Equipping Students for the Continuing Challenges of Learning and Assessment. Keynote address at, Assessment and Feedback Conference. University of Salford, 6 July 2010. [Online]. Available at www.youtube.com/watch?v=e1kcnsRz_rc [Accessed 7 November 2011].

Brown, J., and Isaacs, D. (2005) The World Café: Shaping our Futures Through Conversations that Matter. San Francisco: Berrett-Koehler.

Cheng, J.H.S., and Marsh, H.W. (2010) National Student Survey: Are Differences Between Universities and Courses Reliable and Meaningful? Oxford Review of Education, 36 (6), pp. 693-712.

DfE. 2011. Assessment for Learning. [Online]. Available at: webarchive.nationalarchives.gov. uk/20100612050234/nationalstrategies.standards.dcsf.gov.uk/primary/primaryframework/ assessment/dafl//t/d2da [Accessed 7 November 2011].

Hattie, J., and Timperley, H. (2007) The Power of Feedback. Review of Educational Research, 77, p. 81.

HEFCE. 2011. National Student Survey. [Online]. Available at: www.hefce.ac.uk/learning/nss/ [Accessed 7 November 2011].

Nicol, D., and Owen, C. 2008. Transforming Assessment and Feedback: A Blueprint for Change. Assessment and feedback project workshop. University of Greenwich, London, 7 March 2008.

Nicol, D. (2010) From Monologue to Dialogue: Improving Written Feedback in Mass Higher Education. Assessment and Evaluation in Higher Education. 35 (5), pp. 501-517.

Rust, C., O'Donovan, B., and Price, M. (2005) A Social Constructivist Assessment Process Model: How the Research Literature Shows us this could be Best Practice. Assessment and Evaluation in Higher Education, 30 (3), pp.231-240.

Sheldon, K., and Burke, C. (2010) Encouraging Workplace Innovation using the 'World Cafe' Model. Nursing Management, 17 (7), pp. 14-19.

Sadler, R. (1989) Formative Assessment and the Design of Instructional Systems. Instructional Science, 18, pp. 119-144.

TDA. 2011 Qualifying to Teach:Professional Standards for Qualified Teacher Status. [Online]. Available at: www.tda.gov.uk/training-provider/itt/qts-standards-itt-requirements/guidance/qts-standards.aspx [Accessed 7 November 2011].

World Café. 2011. [Online]. Available at: www.theworldcafe.com/method.html [Accessed 7 November 2011]. 